\title{
A hybrid bacterial foraging-particle swarm optimization technique for solving optimal reactive power dispatch problem
}

\author{
P. Lokender Reddy, Yesuratnam Guduri \\ Department of Electrical Engineering, University College of Engineering, Osmania University, India
}

\begin{tabular}{l} 
Article Info \\
\hline Article history: \\
Received Aug 21, 2019 \\
Revised Feb 19, 2020 \\
Accepted Mar 3, 2020 \\
\hline
\end{tabular}

Keywords:

Bacterial foraging algorithm Hybrid algorithms

Optimal reactive power

dispatch

Particle swarm optimization

\begin{abstract}
This paper presents a hybrid evolutionary computation algorithm termed as hybrid bacterial foraging-particle swarm optimization (HBFPSO) algorithm, to optimal reactive power dispatch (ORPD) problem. HBFPSO algorithm merges velocity and position updating strategy of particle swarm optimization (PSO) algorithm and reproduction and elimination dispersal of bacterial foraging algorithm (BFA). The ORPD is solved for minimization of two objective functions; system real power loss and voltage stability L-index. The objective is minimized by optimally choosing the control variables; generator excitations, tap positions of on-load tap changing transformers and switched var compensators while satisfying their constraints and also the constraints of dependent variables; voltages of all load buses and reactive power generation of all generators. The proposed approach has been evaluated on a standard IEEE 30 bus test system and 24 bus EHV southern region equivalent Indian power system. The results offered by the proposed algorithm are compared with those offered by other evolutionary computation algorithms reported in the recent state of the art literature and the superiority of the proposed algorithm is demonstrated.
\end{abstract}

This is an open access article under the $\underline{C C B Y-S A}$ license.

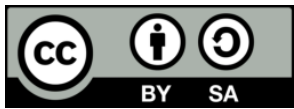

\section{Corresponding Author:}

P. Lokender Reddy,

Department of Electrical Engineering,

University college of Engineering,

Osmania University, Hyderabad, India.

Email: lokender.p@uceou.edu

\section{INTRODUCTION}

Power system design should ensure good quality of reliable power supply which means voltages should be within the specified limits. The voltages at a node are very sensitive to net reactive power of the node. So the reactive power optimization is the way to improve the voltage profile. The optimization of power system is becoming complex because smaller safety margins in generation and transmission due to not matching the generation and transmission facilities with the ever growing demand of power supply.Optimal reactive power dispatch (ORPD) is a multi-objectivenonlinear optimization problem with multiple constraints. There are many conventional techniques such as linear programming, interior point method, non linear programming, quadratic programming etc. are proposed in the literature [1-4]. However, these conventional optimization techniques have several drawbacks such as being trapped in local optima, sensitive to initial conditions and it requires very complex computations of derivative information of objective function.Evolutionary computation algorithms are good alternatives to overcome the drawbacks of conventional algorithms because of their approach of beginning the search with a population of points and random in nature. There are numerous evolutionary computation techniques proposed in the literature [5-7] such as bacteria foraging algorithm, particle swarm optimization, gravitational search algorithm etc., for 
optimal power flow problem with different objective functions. All these algorithms proved better than their conventional counter parts. But each of these algorithms also has their own advantages and disadvantages.

The concept of hybrid algorithm [8-11] is introduced to effectively use the advantages of the two algorithms and also to overcome their disadvantages. In BFA, during the process of chemotaxis, it depends on random search which may delay in obtaining global solution. PSO also has the problem of falling in to local optimum and premature convergence. The randomness in chemotaxis can be overcome by the velocity updating strategy of PSO based on global best and personal best, it improves the speed of convergence random introduction of new solutions in elimination and dispersal of BFA helps to avoid premature convergence of PSO. Amged Saeed El-Wakeel et al., [12] implemented hybrid BF-PSO algorithm by introducing velocity updating strategy after first random tumble. Faqing Zhao et al., [13] applied differential mutation to overcome tumble failure of BFA and slow convergence in chemotaxis step. In this paper, hybrid BF-PSO is proposed by completely replacing the chemotaxis step of BFA with velocity and position updating strategy of PSO algorithm to solve the optimal reactive power dispatch. The proposed algorithm is tested on a standard IEEE 30 bus test system and a practical 24 bus EHV southern region equivalent Indian power system. The evolutionary computation algorithms are random in nature, consistent results are desirable for practical applications. The proposed algorithm is intended to give consistent results with faster convergence.

\section{PROBLEM FORMULATION}

\subsection{Real power loss objective ( $P_{\text {loss }}$ )}

The load flow solution gives all bus voltage magnitudes and angles. Then, the real power loss can be calculated as follows;

$$
P_{\text {loss }}=\sum_{k=1}^{N_{\text {line }}} g_{k}\left(V_{i}^{2}+V_{j}^{2}-2 V_{i} V_{j} \cos \left(\theta_{i}-\theta_{j}\right)\right) M W
$$

where $\mathrm{P}_{\text {loss }}$ is the total real power loss, $\mathrm{N}_{\text {line }}$ is total number of transmission lines. $\mathrm{V}_{\mathrm{i}}$ and $\mathrm{V}_{\mathrm{j}}$ are the voltage magnitudes at the two ends of the $\mathrm{K}^{\text {th }}$ line. $\Theta_{\mathrm{i}}$ and $\Theta_{\mathrm{j}}$ are the voltage angles at the two ends of the $\mathrm{K}^{\text {th }}$ line. $g_{k}$ is conductance of the $\mathrm{K}^{\text {th }}$ line.

\subsection{Voltage stability objective ( $\left.V_{\text {stability }}\right)$}

Voltage stability is measured using L-index;

$$
V_{L}=\sum_{j-g+1}^{n} L_{j}^{2} ; \text { where } L_{j}=\left|1-\sum_{i=1}^{g} F_{j i} \frac{V_{i}}{V_{j}}\right|
$$

where $\mathrm{j}$ indicates all load buses. $\mathrm{v}_{\mathrm{i}}$ and $\mathrm{v}_{\mathrm{j}}$ are voltages at $\mathrm{i}^{\text {th }}$ and $\mathrm{j}^{\text {th }}$ buses. Load flow solution is required to compute L-index. Fjican be obtained from the Ybus matrix as follows;

$$
\left[\begin{array}{c}
\mathbf{I}_{\mathrm{G}} \\
\mathbf{I}_{\mathrm{L}}
\end{array}\right]=\left[\begin{array}{cc}
\mathbf{Y}_{\mathrm{GG}} & \mathbf{Y}_{\mathrm{GL}} \\
\mathbf{Y}_{\mathrm{LG}} & \mathbf{Y}_{\mathrm{LL}}
\end{array}\right]\left[\begin{array}{c}
\mathbf{V}_{\mathrm{G}} \\
\mathbf{V}_{\mathrm{L}}
\end{array}\right]
$$

where $\mathrm{I}_{\mathrm{G}}, \mathrm{I}_{\mathrm{L}}$, and $\mathrm{V}_{\mathrm{G}}, \mathrm{V}_{\mathrm{L}}$ represent currents and voltages at the generator buses and load buses. Rearranging the above equation we get;

$$
\left[\begin{array}{c}
\mathbf{V}_{\mathrm{L}} \\
\mathbf{I}_{\mathrm{G}}
\end{array}\right]=\left[\begin{array}{cc}
\mathbf{Z}_{\mathrm{LL}} & \mathbf{F}_{\mathrm{LG}} \\
\mathbf{K}_{\mathrm{GL}} & \mathbf{Y}_{\mathrm{GG}}
\end{array}\right]\left[\begin{array}{c}
\mathbf{I}_{\mathrm{L}} \\
\mathbf{V}_{\mathrm{G}}
\end{array}\right]
$$

where $F_{L G}=-\left[Y_{L L}\right]^{-1}\left[Y_{L G}\right]$ are the required values. The L-index values are obtained for all load busses for a given load. The range of L-index value is $\left[\begin{array}{ll}0 & 1\end{array}\right]$. As it approaches zero, it indicates improved stability and better system security. As it is closer to 1 , it indicates closer to voltage collapse. So lower L-index is desirable and it should not exceed the maximum limit for any of the load buses.

\subsection{Control variables}

The control variables considered to minimize the objective function aretransformer taps settings of on load tap changing (OLTC) transformers, generator excitation settings and switchable VAR compensating settings. 


\subsection{Constraints}

These control variables have their upper and lower limits. These constraints have to be considered while performing the optimization;

$$
\begin{aligned}
& t_{i j \min } \leq t_{i j} \leq t_{i \text { max }}, i \in T \\
& V_{\text {imin }} \leq V_{i} \leq V_{\text {imax }}, i \in N_{g} \\
& Q_{\text {cimin }} \leq Q_{c i} \leq Q_{\text {cimax }}, \quad i \in N q c
\end{aligned}
$$

where $t_{i j}$ represents the tap settings of OLTC transformer connected between buses $\mathrm{i}-\mathrm{j}$ buses, $\mathrm{Ng}$ represents set of generator buses, $\mathrm{V}_{\mathrm{i}}$ is the voltage of $\mathrm{i}^{\text {th }}$ generator bus, $\mathrm{Q}_{\mathrm{ci}}$ is $\mathrm{i}^{\text {th }}$ bus's reactive power compensation capacity and $\mathrm{N}_{\mathrm{qc}}$ represents set of load buses, which have reactive power support. One more thing need to be considered while minimizing the objective functions is the dependent variables, reactive power output of the generators and voltage of all load buses. They should also not exceed their limits.

$$
\begin{aligned}
& Q_{\text {gimin }} \leq Q_{g i} \leq Q_{\text {gimax }}, \quad i \in N_{g} \\
& V_{\text {imin }} \leq V_{i} \leq V_{\text {imax }}, i \in N_{L}
\end{aligned}
$$

$Q_{g i}$ is the reactive power generated by the $\mathrm{i}^{\text {th }}$ generator. $\mathrm{V}_{\mathrm{i}}$ represents the voltage magnitude at $\mathrm{i}^{\text {th }}$ load bus and $\mathrm{N}_{\mathrm{L}}$ is number of load buses. The values of the control variables set to their bounds if they exceed. The dependent variable constraints are dealt by using penalty factors. By considering the constraints with penalties, the objective functions becomes as follows;

$$
\begin{aligned}
& P_{\text {loss }}=\sum_{k=1}^{N_{\text {line }}} g_{k}\left(V_{i}^{2}+V_{j}^{2}-2 V_{i} V_{j} \cos \left(\theta_{i}-\theta_{j}\right)\right)+\beta_{1} \sum_{i=1}^{N_{L}}\left(\frac{\left(V_{i}-V_{i}^{\mathrm{lim}}\right)}{\left(V_{i}^{\max }-V_{i}^{\min }\right)}\right)^{2}+\beta_{2} \sum_{i=1}^{N_{L}}\left(\frac{\left(Q_{g i}-Q_{g i}^{\mathrm{lim}}\right)}{\left(Q_{g i}^{\max }-Q_{g i}^{\min }\right)}\right)^{2} \\
& V_{L}=\sum_{j=g+1}^{n} L_{j}^{2}+\beta_{1} \sum_{i=1}^{N_{L}}\left(\frac{\left(V_{i}-V_{i}^{\mathrm{lim}}\right)}{\left(V_{i}^{\max }-V_{i}^{\min }\right)}\right)^{2}+\beta_{2} \sum_{i=1}^{N_{L}}\left(\frac{\left(Q_{g i}-Q_{g i}^{\mathrm{lim}}\right)}{\left(Q_{g i}^{\max }-Q_{g i}^{\min }\right)}\right)^{2}
\end{aligned}
$$

$\beta 1$ and $\beta 2$ are penalty factors. Vilim, Qgilim can be expressed as;

$$
V_{i}^{\lim }=\left\{\begin{array}{cc}
V_{i}^{\max }, \quad V_{i}>V_{i}^{\max } \\
V_{i}^{\min }, \quad V_{i}<V_{i}^{\min } \\
V_{i}, \quad \text { others }
\end{array} \quad, \quad Q_{g i}^{\lim }=\left\{\begin{array}{cc}
Q_{g i}^{\max }, & Q_{g i}>Q_{g i}^{\max } \\
Q_{g i}^{\min }, & Q_{g i}<Q_{g i}^{\min } \\
Q_{g i}, & \text { others }
\end{array}\right.\right.
$$

\section{HYBRID BACTERIA FORAGIN-PARTICLE SWARM OPTIMIZATION ALGORITHM}

\subsection{Basic PSO algorithm}

In PSO algorithm, search begins with a population of randomly generated particles, where each particle is a potential solution. The population is updated in every iteration by adding velocity. Velocity is updated by the following equation, where pbest is personal best through iterations and gbest is the overall best of the population.

$$
\begin{aligned}
& v_{i}(t+1)=w \cdot v_{i}(t)+C_{1 r 1}\left(\text { pbest }-x_{i}(t)\right)+C_{2 r 2} \operatorname{rand}\left(\text { gbest }-x_{i}(t)\right) \\
& x_{i}(t+1)=x_{i}(t)+v_{i}(t)
\end{aligned}
$$

Where $\mathrm{w}$ is inertia weight, $\mathrm{C}_{1}$ and $\mathrm{C}_{2}$ are accelerating factors, $\mathrm{r}_{1}$ and $\mathrm{r}_{2}$ are random numbers in the range $[0,1]$, $\mathrm{x}_{\mathrm{i}}$ is theposition of $\mathrm{i}^{\text {th }}$ particle and $\mathrm{v}_{\mathrm{i}}$ is the velocity to be added to the $\mathrm{i}^{\text {th }}$ particle.

\subsection{Basic BF algorithm}

In the original BFA, evolution of initial population of bacteria follows foraging strategy of bacteria which consists of chemotactic step, reproduction step and elimination and dispersion step. Chemotactic step simulates the movement of E.coli bacteria through tumbling and swimming via flagella. The chemotaxis movement of the bacterium can be represented as: 


$$
\theta^{i}(j, k, l)=\theta^{i}(j, k, l)+c(i) \phi(j) ; \text { where } \phi(j)=\frac{\Delta(i)}{\sqrt{\Delta^{T}(i) \Delta(i)}}
$$

where $e^{i}(j, k, l)$ is the position vector of $\mathrm{i}^{\text {th }}$ bacterium for the $\mathrm{j}^{\text {th }}$ chemotactic step, $\mathrm{k}^{\text {th }}$ reproduction step and $1^{\text {th }}$ elimination and dispersal step. $c(i)$ is the random step size specified by the tumble. $\phi(j)$ is angle of direction at $\mathrm{j}^{\text {th }}$ tumble step. If the fitness at the position $e^{i}(j+1, k, l)$ is greater than the fitness at the position $e^{i}(j, k, l)$ then the bacterium takes another few steps in the direction specified by swim length. If the fitness at position $e^{i}(j+1, k, l)$ is less than the fitness at the positione $e^{i}(j, k, l)$ then the bacterium does not go for swim, it finds another direction through tumble. Many such tumble failures results in slowing down the algorithm.

\subsection{Proposed hybrid BF-PSO algorithm}

BF-PSO algorithm combines the PSO ability of exchanging social information and BFA ability to find new solution by elimination and dispersion. The tumble direction in chemotactic movement of BFA is calculated by using global best and each bacteria personal best as done in PSO. It avoids complex calculations and also randomness which delay the convergence. In reproduction step, all bacteria, which are gone through chemotactic step, are sorted and best half of bacteria are retained and worst half of bacteria die. To reduce the chance to trap in local minimum, which is the case in PSO algorithm, certain number of replicated bacteria is randomly dispersed in to the search space at a certain rate. This measure can increase the rate of achieving optimal solution and avoid premature convergence.

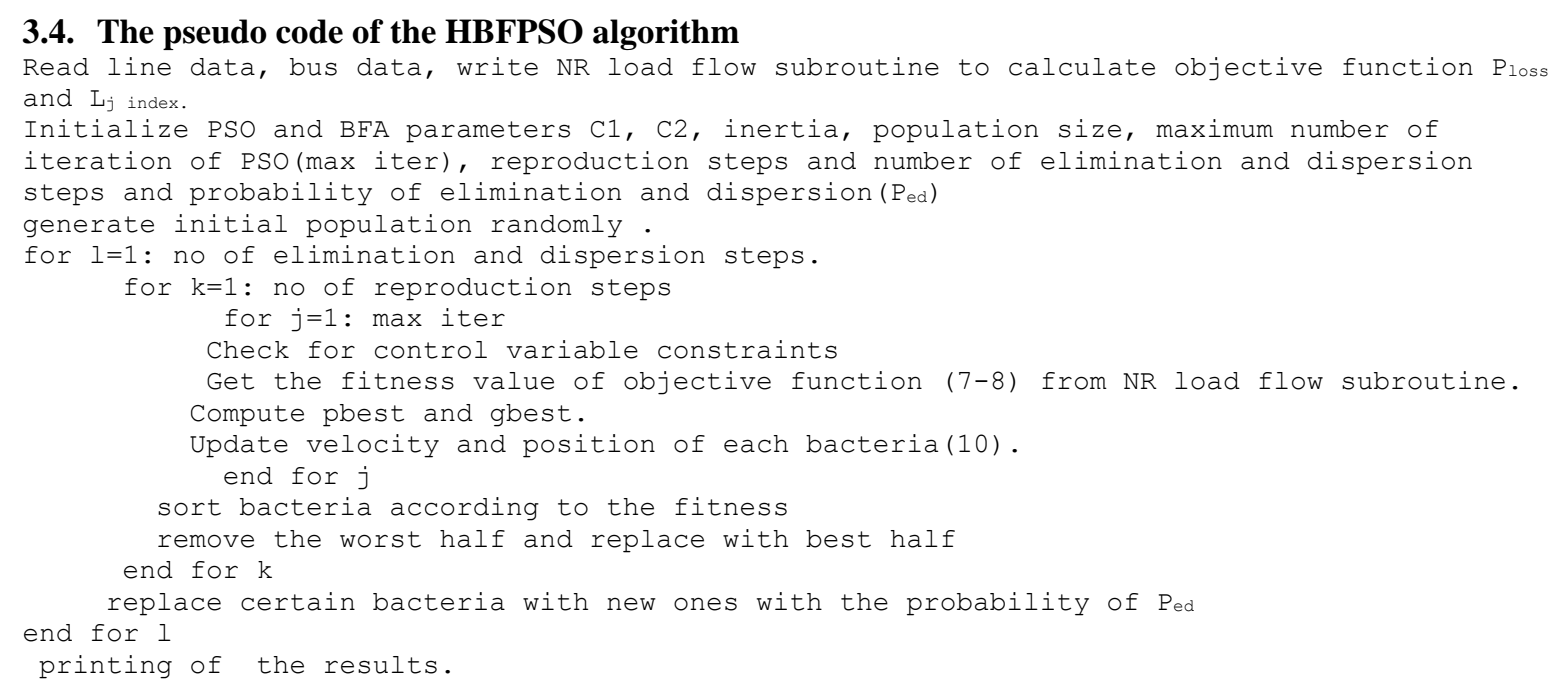

\section{RESULT AND DISCUSSION}

Simulations are conducted for BFA, PSO and HBFPSO algorithms in MATLAB R2009b software on a $1.9 \mathrm{GHz}, 4 \mathrm{~GB}$ RAM, i3 processor personal computer. The obtained results are also compared with other evolutionary algorithms reported in the literature such as artificial bee colony algorithm (ABC) [14], bat algorithm (BA) [14], grey wolf optimizer (GWO) [14] and ant lion optimizer (ALO) [14]. Evolutionary computation techniques are random in nature so 30 consecutive runs are executed and best, worst, mean and standard deviation of the results are presented.

\subsection{IEEE 30 bus system}

Bus data, line data and initial values of control variables are taken from [15]. It consists of 30 buses, 41 branches, 6 generators, 4 OLTC transformers, and 9 buses with capacitor banks. Buses 1, 2, 5, 8, 11, and 13 are generator buses. Capacitor bank is installed at buses 10,12, 15, 17, 20, 21, 23, 24, and 29. Branches (4-12), (6-9), (6-10), and (28-27) are equipped with OLTC transformers. The allowable range for the voltages of generator buses and load buses is [0.95 1.1] Operating range of all OLTCs is [0.9 1.1]. The range of capacitor banks in MVAR is [0 5].

The simulation results for $\mathrm{P}_{\text {loss }}$ objective are given in Table 1. The Proposed HBFPSO algorithm reduced the power loss from initial $5.812 \mathrm{MW}$ to $4.527 \mathrm{MW}$ which indicates $22 \%$ reduction from base case. There is $0.06 \mathrm{MW}$ power loss reduction from the best of other evolutionary algorithms (4.59MW by ALO) 
presented in the literature. Proposed algorithm is also giving lowest L-index value in comparison with all other evolutionary computation techniques. Optimal settings of controllers are presented in the Table 1.

Table 1. Optimal settings of control variables, $\mathrm{P}_{\text {loss }}$ and maximum L-index for $\mathrm{P}_{\text {loss }}$ objective

\begin{tabular}{|c|c|c|c|c|c|c|c|c|c|}
\hline & & Initial & BA & GWO & $\mathrm{ABC}$ & ALO & BFA & PSO & HBFPSO \\
\hline Generator & V1 & 1.05 & 1.1 & 1.1 & 1.1 & 1.1 & 1.1 & 1.1 & 1.1 \\
\hline \multirow[t]{5}{*}{ excitations } & $\mathrm{V} 2$ & 1.04 & 1.094 & 1.0938 & 1.0971 & 1.0953 & 1.0887 & 1.0956 & 1.0951 \\
\hline & V5 & 1.01 & 1.074 & 1.0737 & 1.0866 & 1.0767 & 1.0701 & 1.0783 & 1.0759 \\
\hline & V8 & 1.01 & 1.076 & 1.0797 & 1.08 & 1.0788 & 1.069 & 1.0803 & 1.0773 \\
\hline & VG11 & 1.05 & 1.1 & 1.1 & 1.085 & 1.1 & 1.0612 & 1.1 & 1.1 \\
\hline & VG13 & 1.05 & 1.1 & 1.0944 & 1.1 & 1.1 & 1.095 & 1.1 & 1.1 \\
\hline OLTC & T6-9 & 1.078 & 0.95 & 0.98 & 1.07 & 1.01 & 0.9792 & 1.075 & 1.0086 \\
\hline \multirow[t]{3}{*}{ transformers } & T6-10 & 1.069 & 1.03 & 0.97 & 0.95 & 0.99 & 0.9091 & 0.9 & 0.9664 \\
\hline & T4-12 & 1.032 & 0.99 & 1.02 & 1.02 & 1.02 & 0.94 & 1 & 0.9834 \\
\hline & T28-27 & 1.068 & 0.97 & 0.99 & 1.01 & 1 & 0.9572 & 1 & 0.9757 \\
\hline SVC & QC10 & 0 & 5 & 2 & 5 & 4 & 4 & 5 & 5 \\
\hline \multirow[t]{8}{*}{ settings } & QC12 & 0 & 0 & 5 & 0 & 2 & 3 & 1 & 5 \\
\hline & QC15 & 0 & 5 & 4 & 2 & 4 & 1 & 1 & 5 \\
\hline & QC17 & 0 & 5 & 4 & 5 & 3 & 4 & 5 & 5 \\
\hline & QC20 & 0 & 0 & 4 & 4 & 2 & 2 & 5 & 5 \\
\hline & QC21 & 0 & 0 & 0 & 5 & 4 & 0 & 1 & 5 \\
\hline & QC23 & 0 & 0 & 5 & 4 & 3 & 3 & 5 & 5 \\
\hline & QC24 & 0 & 5 & 3 & 5 & 5 & 0 & 5 & 5 \\
\hline & QC29 & 0 & 0 & 3 & 4 & 5 & 4 & 5 & 4 \\
\hline \multirow{5}{*}{$\begin{array}{l}\text { Objective } \\
\text { function and } \\
\text { statistical } \\
\text { parameters }\end{array}$} & Best $\mathbf{P}_{\text {loss }}$ & 4.812 & 4.628 & 4.612 & 4.611 & 4.59 & 4.694 & 4.577 & 4.527 \\
\hline & worst $\mathrm{P}_{\text {loss }}$ & NA & NA & NA & NA & NA & 5.138 & 4.747 & 4.61 \\
\hline & Mean $\mathrm{P}_{\text {loss }}$ & NA & NA & NA & NA & NA & 4.906 & 4.644 & 4.552 \\
\hline & Standard deviation & NA & NA & NA & NA & NA & 0.1169 & 0.0564 & 0.002 \\
\hline & $\mathrm{L}_{\max }$ & 0.1716 & 0.1247 & 0.1303 & 0.1326 & 0.1307 & 0.1193 & 0.1186 & 0.115 \\
\hline
\end{tabular}

The simulation results for Vstability objective are given in Table 2. The proposed HBFPSO algorithm reduced the maximum of L-index value from initial 0.1716 to 0.1132 , which is lowest in comparison with PSO, BFA, and other evolutionary computation algorithms from the literature. It is also giving better Ploss for Vstability objective. Optimal settings of controllers are presented in the Table 2. The statistical parameters clearly indicate the consistency of the proposed algorithm, there is significant reduction in standard deviation and mean values of the proposed algorithm in comparison to basic algorithms. The convergence characteristics are shown in Figure 1.

Table 2. Optimal settings of control variables, maximum L-index and $\mathrm{P}_{\text {loss }}$ for $\mathrm{V}_{\text {stability }}$ objective

\begin{tabular}{|c|c|c|c|c|c|c|c|c|c|}
\hline & & Initial & BA & GWO & $\mathrm{ABC}$ & ALO & BFA & PSO & HBFPSO \\
\hline Generator & VG1 & 1.05 & 1.097 & 1.0965 & 1.0829 & 1.0992 & 1.0912 & 1.1 & 1.1 \\
\hline \multirow[t]{5}{*}{ excitations } & VG2 & 1.04 & 1.093 & 1.0807 & 1.073 & 1.0948 & 1.0813 & 1.0982 & 1.0914 \\
\hline & VG3 & 1.01 & 1.049 & 1.0693 & 1.0759 & 1.0975 & 1.0173 & 1.1 & 1.1 \\
\hline & VG4 & 1.01 & 1.071 & 1.0624 & 1.0744 & 1.0997 & 1.0721 & 1.1 & 1.0683 \\
\hline & VG5 & 1.05 & 1.06 & 1.0977 & 1.1 & 1.0979 & 1.0306 & 0.95 & 1.0999 \\
\hline & VG6 & 1.05 & 1.097 & 1.0927 & 1.0804 & 1.1 & 1.0655 & 1.1 & 1.0794 \\
\hline OLTC & T6-9 & 1.078 & 1.09 & 0.96 & 1.03 & 1.04 & 0.9 & 0.9 & 1.0043 \\
\hline \multirow[t]{3}{*}{ transformers } & T6-10 & 1.069 & 0.9 & 1.01 & 0.92 & 0.95 & 0.9236 & 0.9 & 0.9017 \\
\hline & $\mathrm{T} 4-12$ & 1.032 & 1.1 & 0.97 & 0.92 & 0.98 & 0.9 & 0.975 & 0.9546 \\
\hline & T28-27 & 1.068 & 0.93 & 0.94 & 0.97 & 0.97 & 0.9269 & 0.975 & 0.9648 \\
\hline SVC & QC10 & 0 & 3 & 2 & 5 & 5 & 3 & 5 & 4.9103 \\
\hline \multirow[t]{9}{*}{ settings } & QC12 & 0 & 4 & 1 & 5 & 3 & 3 & 5 & 4.6458 \\
\hline & QC15 & 0 & 3 & 1 & 5 & 3 & 0 & 5 & 4.8684 \\
\hline & QC17 & 0 & 5 & 2 & 4 & 4 & 4 & 5 & 4.9459 \\
\hline & QC20 & 0 & 5 & 2 & 5 & 3 & 2 & 5 & 4.3441 \\
\hline & QC21 & 0 & 0 & 1 & 3 & 2 & 0 & 5 & 4.8882 \\
\hline & QC23 & 0 & 0 & 4 & 4 & 1 & 3 & 5 & 4.9987 \\
\hline & QC24 & 0 & 0 & 4 & 4 & 2 & 1 & 1 & 4.6363 \\
\hline & QC29 & 0 & 3 & 4 & 5 & 4 & 1 & 5 & 4.9072 \\
\hline & $\mathrm{P}_{\text {loss }}(\mathrm{MW})$ & 5.812 & 5.0748 & 4.8269 & 4.9688 & 4.8693 & 5.9247 & 5.825 & 4.88 \\
\hline Objective & Best $\mathrm{L}_{\max }$ & 0.1716 & 0.1191 & 0.118 & 0.1161 & 0.1161 & 0.1174 & 0.1142 & 0.1132 \\
\hline function and & Worst $\mathrm{L}_{\max }$ & NA & NA & NA & NA & NA & 0.1258 & 0.1198 & 0.1153 \\
\hline statistical & Mean $\mathrm{L}_{\max }$ & NA & NA & NA & NA & NA & 0.1212 & 0.1157 & 0.1142 \\
\hline parameters & STD & NA & NA & NA & NA & NA & 0.0022 & 0.0015 & 0.0006 \\
\hline
\end{tabular}



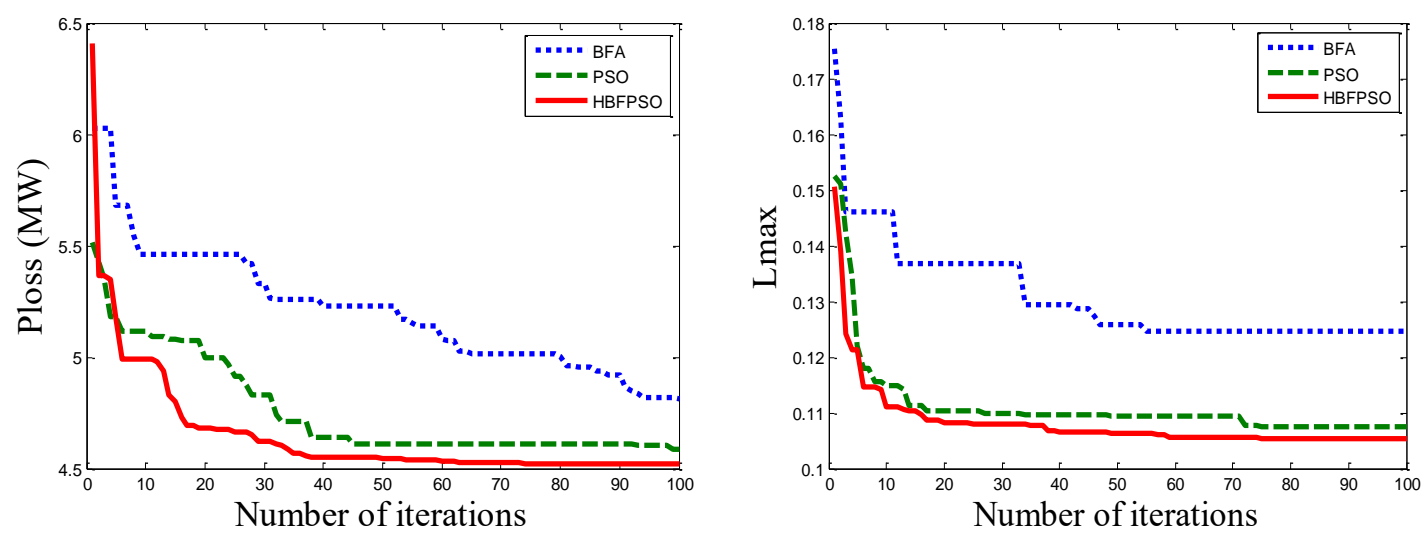

Figure 1. Convergence characteristics of BFA, PSO and HBFPSO for $\mathrm{P}_{\text {loss }}$ and $\mathrm{V}_{\text {stability }}$ objectives

\subsection{4 node system}

24 bus EHV southern region equivalent Indian power system shown in Figure 2. It consists of 4 generator buses, 16 transmission lines, 8 load buses, 11 transformers, 4 shunt capacitors and 17 shunt reactors. Reactive power sources are installed at buses 5, 6, 7 and 8. Branches (14-8), (16-5), (19-6), (20-7), (22-13), (23-9), and (18-10) are equipped with OLTC transformers. Lower and upper bound's for generator voltages are $0.95 \mathrm{pu}$ to $1.1 \mathrm{pu}$ with a step size of 0.0125 . Discrete tap positions of transformer being 0.900 to 1.05 in steps of 0.0125. Maximum operating limits for capacitors are 25, 20, 30, 20 (in MVAr) at the buses 5, $6,7,8$ respectively and a step size of 5 . The simulations are conducted at heavy load condition by increasing $20 \%$ of reactive load from its base load condition. The objective values are shown in bold because they are the quantities of interest in comparison.

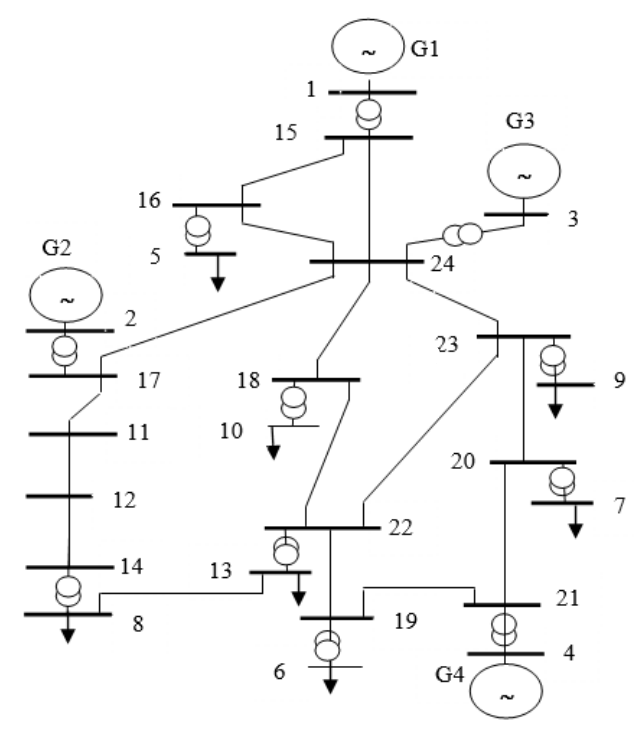

Figure 2. 24 Bus equivalent EHV Indian power system

Table 3 shows the simulation results for both objectives Ploss and $\mathrm{V}_{\text {stability. The proposed HBFPSO }}$ method reduced the real power loss value from base value $73.62 \mathrm{MW}$ to $53.69 \mathrm{MW}$. The reduction offered by proposed algorithm is nearly 20MW from base case. The proposed HBFPSO algorithm is proven superior when compared to other evolutionary algorithms PSO and BFA in terms of best, average and worst values. There is only slight reduction $0.05 \mathrm{MW}$ in terms of best value offered by HBFPSO to the best Ploss offered by PSO but there is a significant reduction $0.55 \mathrm{MW}$ in terms of Mean values. The low value of standard deviation indicates the consistency of proposed algorithm for multiple runs. It can also be noted that the proposed algorithm is giving lowest values of the voltage stability index $\left(\mathrm{V}_{\mathrm{L}}\right)$ for $\mathrm{P}_{\text {loss }}$ objective when compared to basic algorithms. Convergence characteristics are shown in Figure 3. 
Table 3. Optimal control variables settings and power system parameters for $\mathrm{P}_{\text {loss }}$ objective

\begin{tabular}{lllllllll}
\hline Controller & \multicolumn{2}{l}{ Initial settings } & \multicolumn{2}{l}{$\mathrm{P}_{\text {loss }}$ objective } & \multicolumn{3}{c}{ Controller } & \multicolumn{2}{l}{$\mathrm{V}_{\text {stability }}$ objective } \\
& & PSO & BFA & HBF-PSO & & PSO & BFA & HBF-PSO \\
\hline T16-5 & 1 & 0.95 & 0.9625 & 0.95 & T16-5 & 0.9 & 0.9 & 0.9125 \\
T19-6 & 1 & 0.975 & 0.9625 & 0.975 & T19-6 & 0.9125 & 0.9625 & 0.925 \\
T20-7 & 1 & 0.975 & 0.9875 & 0.9625 & T20-7 & 0.9125 & 1.05 & 0.9125 \\
T14-8 & 1 & 0.9625 & 0.9875 & 0.975 & T14-8 & 0.9 & 0.975 & 0.9125 \\
T23-9 & 1 & 0.975 & 1.0375 & 0.975 & T23-9 & 0.9375 & 0.95 & 0.9375 \\
T18-10 & 1 & 1 & 0.9625 & 0.9875 & T18-10 & 0.9375 & 1.05 & 0.9375 \\
T22-13 & 1 & 0.9625 & 0.95 & 0.9625 & T22-13 & 0.9 & 0.9 & 0.9 \\
QC5 & 0 & 25 & 25 & 25 & QC5 & 15 & 25 & 25 \\
QC6 & 0 & 20 & 20 & 20 & QC6 & 20 & 20 & 20 \\
QC7 & 0 & 30 & 30 & 30 & QC7 & 25 & 25 & 30 \\
QC8 & 0 & 20 & 20 & 20 & QC8 & 20 & 20 & 20 \\
V1 & 1 & 1.05 & 1.05 & 1.05 & V1 & 1.05 & 1.05 & 1.05 \\
V2 & 1 & 1.05 & 1.0375 & 1.05 & V2 & 1.05 & 1.0375 & 1.05 \\
V3 & 1 & 1.05 & 1.0375 & 1.05 & V3 & 1.05 & 1.0375 & 1.05 \\
V4 & 1 & 1.05 & 1.05 & 1.05 & V4 & 1.05 & 1.05 & 1.05 \\
Vmin & 0.794 & 0.9684 & 0.964 & 0.9658 & Vmin & 1.0431 & 1.0134 & 1.0408 \\
Lmax & 0.633 & 0.4528 & 0.4587 & 0.4527 & Lmax & 0.4388 & 0.4495 & 0.4378 \\
VL & 3.1424 & 1.7353 & 1.7908 & 1.7309 & Ploss & 61.85 & 60.21 & 60.24 \\
Ploss(best) & $\mathbf{7 3 . 6 2}$ & $\mathbf{5 3 . 7 4}$ & $\mathbf{5 5 . 5 4}$ & $\mathbf{5 3 . 6 9}$ & V (best) & $\mathbf{1 . 6 6 9 4}$ & $\mathbf{1 . 7 6 8 9}$ & $\mathbf{1 . 6 5 8 7}$ \\
Ploss(worst) & NR & 56.16 & 58.844 & 54.46 & V (worst) & 1.7869 & 1.9571 & 1.748 \\
Ploss(Mean) & NR & 54.36 & 57.39 & 53.81 & V (Mean) & 1.707 & 1.837 & 1.6868 \\
STD & NR & 0.542 & 0.951 & 0.235 & STD & 0.0313 & 0.0484 & 0.0238 \\
\hline
\end{tabular}

The voltage stability index $\left(\Sigma \mathrm{L}^{2}\right)$ offered by the proposed HBFPSO method is 1.6587 , which is $48 \%$ less from base case. In comparison with other evolutionary algorithms, the best value offered by HBFPSO is $0.65 \%$ less when compared with PSO, $6 \%$ less when compared with BFA algorithm. The Mean value of 30 runs of HBPSO is 1.6868 which is $1.2 \%$ less compared to PSO and $8 \%$ less compared to BFA. Better Mean values of the proposed HBFPSO and the low value of standard deviation indicates the consistency of proposed algorithm for multiple runs.
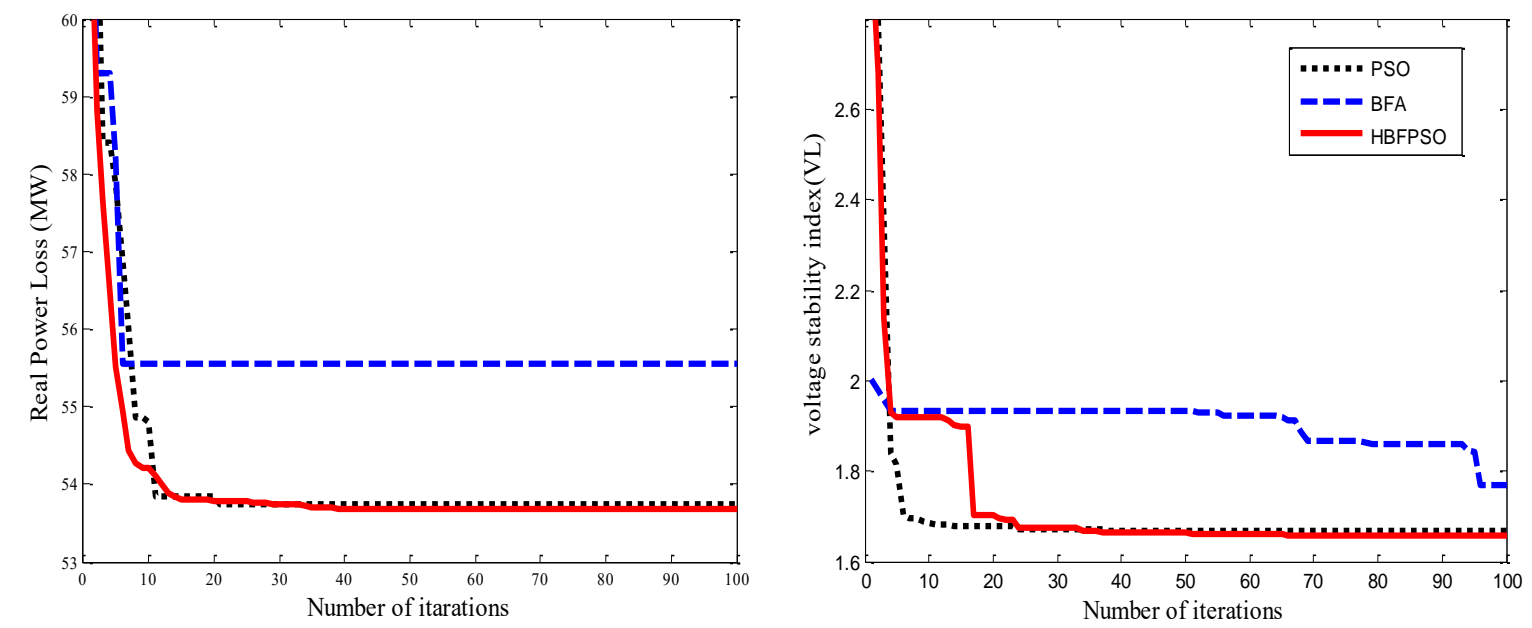

Figure 3. Convergence characteristics of BFA, PSO and HBFPSO for $\mathrm{P}_{\text {loss }}$ and $\mathrm{V}_{\text {stability }}$ objectives

\section{CONCLUSION}

Reactive power optimization with hybrid BF-PSO is proposed for the minimization of two objectives real power loss and voltage stability index. The proposed algorithm is tested on standard IEEE 30 bus system and a practical 24 bus Indian power system. Results obtained for multiple runs show that the proposed hybrid algorithm is not only giving better but more importantly giving consistent results when compared with basic BFA and PSO algorithms and also other evolutionary computation algorithms reported in the literature. The proposed hybrid algorithm is also successful in overcoming the limitations of basic PSO and BFA algorithm and achieve near optimal solution. 


\section{REFERENCES}

[1] J. Qiu and S. M. Shahidehpour, "A new approach for minimizing power losses and improving voltage profile," IEEE Transactions on Power Systems, vol. 2, no. 2, pp. 287-295, 1987.

[2] D. Thukaram, K. Parthasarathy, H. P. Khincha, N. Udupa, and A. Bansilal, "Voltage stability improvement: Case studies of Indian power networks," Electric Power Systems Research, vol.44, no. 1, pp.35-44, 1998

[3] A. Lomi, D. Thukaram, "Optimum reactive power dispatch for alleviation of voltage deviations,"Telecommunication, Computing, Electronics and Control, vol. 10, no.2, pp.257-264, 2012.

[4] T. Dhadbanjan and G. Yesuratnam, "Comparison of optimum reactive power schedule with different objectives using LP technique,"International Journal of Emerging Electric Power Systems, vol. 7, no. 3, pp. 1-29, 2006.

[5] X. Wu,Z. Piao,Y. Liu, and H. Luo, "Reactive power and voltage control based on improved particle swarm optimization in power system," 8 th World Congress on Intelligent Control and Automation, Jinan, pp. 5291-5295, 2010.

[6] M. Tripathy and S. Mishra, "Optimizing voltage stability limit and real power loss in a large power system using bacteriaforaging," 2006 International Conference on Power Electronic, Drives and Energy Systems, New Delhi, pp. 16, 2006.

[7] M. K. M. Zamani, I. Musirin, M. S. Omar, S. I. Suliman, N. A. Md. Ghani, and N. A. M. Kamari, "Gravitational search algorithm based technique for voltage stability improvement," Indonesian Journal of Electrical Engineering and Computer Science, vol. 9, no. 1, pp.123-130, 2018.

[8] T. O. Ting, K. P. Wong, and C. Y. Chung, "Hybrid constrained genetic algorithm/particle swarm optimisation load flow algorithm," IET Generation, Transmission \& Distribution, vol. 2, no. 6, pp. 800-812, 2008.

[9] M. M. A. Alqadasi, S. M. Othman, M. F. Rahmat, and F. Abdullah, "Optimization of PID for industrial electro-hydraulic actuator using PSOGSA," TELKOMNIKATelecommunication, Computing, Electronics and Control, vol. 17, no. 5, pp. 2625-2635, 2019.

[10] F. Laouafi, A. Boukadoum, and S. Leulmi, "A hybrid formulation between differential evolution and simulated annealing algorithms for optimal reactive power dispatch,"Telecommunication, Computing, Electronics and Control, vol. 16, no. 2, pp. 513-524, 2018.

[11] G. Xiao, H. Liu, Y. Zhou, and Y. Guo, "Research on chaotic firefly algorithm and the application in optimal reactive power dispatch,"Telecommunication, Computing, Electronics and Control,vol. 15, no. 1, pp. 93-100, 2017.

[12] A. S. El-Wakeel, A.El-E. K. M. Ellissy, and A. M. Abdelhamed, "A hybrid bacterial foraging-particle swarm optimization technique for optimal tuning of proportional-integral-derivative controller of a permanent magnet brushless DC motor," Electric Power Components and Systems, vol. 43, no. 3, pp. 309-319, 2015.

[13] F. Zhao, X. Jiang, C. Zhang, and J. Wang, "A chemotaxis enhanced bacterial foraging algorithm and its application in job shop scheduling problem," International Journal Computer Integrated Manufacturing, vol. 28, no. 10, pp, 1106-1121, 2015.

[14] S. Mouassa, T. Bouktir, and A. Salhi, "Ant lion optimizer for solving optimal reactive power dispatch problem in power systems,"Engineering Science and Technology, an International Journal, vol. 20, no. 3, pp. 885-895, 2017.

[15] K.Y. Lee, Y.M. Park, and J.L. Oritz, "Optimal real and reactive power dispatch,"Electric Power Research, vol. 7, no. 3, pp. 201-212, 1984.

\section{BIOGRAPHIES OF AUTHORS}

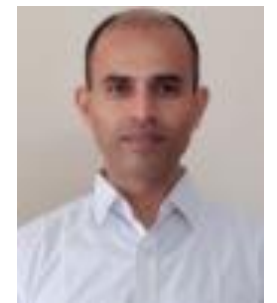

P. Lokender Reddy received B. Tech. degree in electrical and electronics engineering from Jayaprakash Narayana college of Engineering, Mahabub Nagar, India in 2001. He received M.Tech. degree in 2004 from National Institute of Technology, Calicut in the field of instrumentation and control systems. Currently he is working as assistant professor, and also working towards his Ph.D. in the Department of Electrical Engineering, University College of Engineering, Osmania University, Hyderabad. His research interests include evolutionary computation, reactive power optimization and voltage stability.

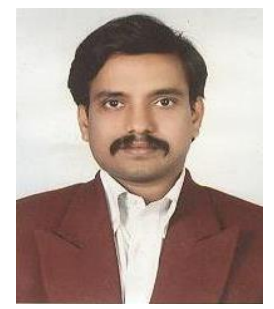

Yesuratnam Guduri received B.Tech. degree in electrical and electronics engineering from Jawaharlal Nehru Technological University, Hyderabad, India in 1995. He received M.Tech. degree in 1998 from Regional Engineering College, Warangal in the field of power systems. $\mathrm{He}$ received Ph.D. degree from the Department of Electrical Engineering, Indian Institute of Science, Bangalore in 2007. Currently he is working as professor in the Department of Electrical Engineering, University College of Engineering, Osmania University, Hyderabad. His research interests include computer aided power system analysis, reactive power optimization, voltage stability and artificial intelligence applications in power systems. 